\title{
Students' Perspectives on the Use of Differentiated Assessment Tool: Results from an Explanatory Sequential Mixed-Method Pilot Study
}

\author{
Christye Majuddin \\ Universiti Putra Malaysia, Malaysia \\ ORCID: 0000-0002-9974-7977 \\ Mas Nida Md. Khambari \\ Universiti Putra Malaysia, Malaysia \\ ORCID: 0000-0002-7517-9442 \\ Su Luan Wong \\ Universiti Putra Malaysia, Malaysia \\ ORCID: 0000-0001-7824-314X \\ Norliza Ghazali \\ Universiti Putra Malaysia, Malaysia \\ ORCID: 0000-0002-4735-1209 \\ Noris Mohd. Norowi \\ Universiti Putra Malaysia, Malaysia \\ ORCID: 0000-0001-7420-5867
}

\begin{abstract}
While educators worldwide are moving towards the universal design for learning, it is also essential to ensure learners are suitably assessed. Assessments and learning profoundly reciprocate one another as assessment may inform the learning practices, and vice versa. Resonating the aforesaid view, PutraPacer was developed as a customizable tool to empower instructors in embracing differentiated assessment. The objective of this pilot study is to elicit feedback on the use of PutraPacer as a differentiated assessment tool among a group of undergraduate students at a higher education institution. Drawing on the UTAUT model, this study employs an explanatory sequential mixed-method design to gather both quantitative and qualitative data. The quantitative findings show that the mean values for performance expectancy, effort expectancy, social influences, and behavioural intention to use PutraPacer are ranged between 3.56 and 3.67. Based on the Pearson's correlation coefficient, there are strong association between performance expectancy, effort expectancy, social influences with behavioural intention to use PutraPacer as a differentiated assessment tool. The qualitative findings reveal that the students perceived PutraPacer as a user-friendly and a learning tool that promotes individualized learning experience and supports students with different abilities, and iii) a good platform for practices, quizzes, and revision.
\end{abstract}

Keywords: alternative assessment, differentiated assessment, learners' diversity, explanatory sequential mixed method 


\section{INTRODUCTION}

Ensuring rock solid clarity about where we want students to end up as a result of a sequence of learning is fundamental to educational success. Remembering that we cannot reach the mind we do not engage ought to be a daily compass for educational planning (Tomlinson, 2001, p. 1).

Assessment is deemed important as a proof that learning happens, regardless of students' background, characteristics, and ability per se. The aforementioned quote can be translated that assessment is a powerful tool to determine whether an instructor is engaged with the students' minds and whether students are actually learning. Other than getting evidence that students learned, assessment can benefit the assessor (Nasri et al., 2010), namely the instructor, to improve his/her pedagogical qualities and enhance his/her scholarship of teaching and learning. Besides that, assessment most importantly allows instructors to have a better picture of their learners' abilities as it allows continuous interaction between assessment and instruction (Al-Mahrooqi \& Denman, 2018).

An alternative assessment is a student-centered approach that focuses on the level of the application of knowledge and skills to real life, taking the individual features of the students into consideration (Caliskan \& Kasikci, 2010). One of the approaches to alternative assessment, namely differentiated assessment, is the approach put forth in this research to address mixed-ability and diverse learning styles. Differentiation stems from beliefs about differences among learners (Algozzine \& Anderson, 2007; Lawrence-Brown, 2004; Tomlinson, 2001), like background, characteristics, learning style, needs, preferences, interests, and abilities. The role of instructor, therefore, has amplified in a multitude of forms to address these diversities. As for students, differentiated assessment gives them the opportunity to choose how they want to be assessed and prove that they have learned (NSW Education Standards Authority, n.d.; Tomlinson, 2001). It celebrates students' diversity and acknowledges their mixed learning ability.

To ensure the needs of diverse learners are met, educators bear the responsibilities to plan strategically to achieve targeted standards (Suprayogi et al., 2017; Tomlinson, 2015). One of the responsibilities is to apply the principle of differentiation in teaching and learning (Gregory \& Chapman, 2013). Differentiation in assessment is an approach to alternative assessment which attempts to address differences among learners. Time and again, studies have shown that learners are different not only in terms of characteristics and background, but also in learning abilities, styles, preferences, needs, adult support, experience, and interests (Algozzine \& Anderson, 2007; Kaur et al., 2018; Lawrence-Brown, 2004; Moon et al., 2020; Tomlinson, 2001). Differentiated assessment, therefore, provides these learners with flexibility in skills development, levels of knowledge acquisition, and types of assessments assumed by them (Varsavsky \& Rayner, 2013). Recent studies which shared the same notion also emphasize on the need to transform teaching and learning methods toward innovation that is based on information and technology (Anggraeni, 2018; Gulicheva et al., 2017; Lawrence et al., 2019). When teaching and learning methods are transformed, the way learners are assessed should also come hand-in-hand.

However, the Malaysian education predominantly uses standardized test as a form of assessment although its practice has been subjected to heavy criticism (Chin et al., 2019; John, 2018; Loh \& Teo, 2017; Wilson \& Narasuman, 2020). Standardized tests which are widely practiced in examination-oriented education cause excessive learning fatigue, and distorting learners from growing within their capabilities and educators from being creative (Chan et al., 2018). Most importantly, standardized tests fail to address learners' diverse and individual needs (Noman \& Kaur, 2014; Tomlinson, 2015) as this form of assessment "are not designed to address variance in readiness, interest, or learning profile" (Tomlinson \& Moon, 2013, p. 76). Surprisingly, not only compassion for new knowledge has faded among learners when education is examination-driven, but the compassion for teaching among educators were also diluted as a study found that teachers do not know how to let their students learn if there were no examinations (Ho et al., 2012).

Realizing the disadvantages of standardized tests, the practice of-high-staked standardized examination is abolished through the national education reform. The Ministry of Education is currently advocates a holistic approach to assessment and highlights the practice of assessment for learning or formative assessment in all levels (Ministry of Education, 2013, 2015). The implementation of assessment for learning requires teachers 
to assess their students using alternative methods that go beyond worksheets and written assignments (Chin et al., 2019). Eventually, this opens more opportunities for teachers to exercise differentiation in the classroom since effective differentiation of instruction is inseparable with the practice of formative assessment (Tomlinson \& Moon, 2013).

Previous research on alternative assessments in Malaysia show that educators have employed various tools for formative assessments. For examples rubrics, portfolios, online games, and concept maps (Alias \& Osman, 2014; Ghani et al., 2017; Swaran Singh \& Abdul Samad, 2012). However, it is found that there is no generic, systematic and dedicated tools available yet for educators to employ differentiated assessment in classrooms in Malaysia. Therefore, the main objective of this study is to elicit students' feedback on the use of a differentiated assessment tool named PutraPacer.

\section{ASSESSMENTS PRACTICES, ALTERNATIVE, AND DIFFERENTIATED ASSESSMENTS}

To avoid the ramifications from examination-driven practices, educators therefore have to be knowledgeable on alternative practices and the underlying theory associated with them (Janisch et al., 2007) that can give just to the learners. With the on-going efforts of moving away from the examination-driven methods, alternative assessments methods emerged. Scholars believed that the use of alternative assessment could assist in developing skills needed in the 21st century which includes problem-solving abilities and higherorder thinking (Alias \& Osman, 2015; Ghani et al., 2017). Alternative assessment also encourages learners to be autonomous in their learning in a way that they can explore their own ideas, self-evaluate their own learning styles, and identify their own strengths and weaknesses (Gozuyesil \& Tanriseven, 2017; Swaran Singh \& Abdul Samad, 2012); hence, supporting flexibility and meaningful experience in learning. Swaran Singh and Abdul Samad (2012) assert alternative assessment could help teachers to obtain information about their students' strengths and weaknesses since these attributes are demonstrated over time. Earlier study by Mohtar (2010) agrees that information on students' achievement and progress are more reliable and valid if they are assessed using alternative assessment. The authentic data of students' achievement is important whereby it can be used for teachers to plan or to improve their teaching strategies (Koshy, 2013).

As a form of alternative assessment, differentiated assessment is essential in order to reach the needs of diverse learners. Through differentiated assessment, each student is given the opportunity to choose how they would like to be assessed, and how to develop their skills based on their own learning styles and talents (Moon et al., 2020; Varsavsky \& Rayner, 2013). Autonomous learning skills can be inculcated by making students aware of their strengths and weakness in relative to the learning goals and self-regulate their own learning to move forward and eventually achieve the targeted learning goals. Moreover, differentiated assessment allows flexibility in learning progress whereby there is no obligatory timeline for students to adhere to (Moon et al., 2020). Even long before the recent education reform pinpoints the need to shift the assessment practise into a holistic approach that values learner's diversity, Gardner (1992) who introduced the multiple intelligence theory strongly believed that teacher training should put emphasis on individual differences because assessments that neglect differences among individuals are outdated.

\section{THE DEVELOPMENT OF PUTRAPACER AS A DIFFERENTIATED ASSESSMENT TOOL}

With the emergence of technology, the use of web-based assessment and computer-based assessment (CBA) are prevalent in education nowadays due to its practicality and advantages in improving learning performance, encouraging personalized learning, supporting higher order thinking skills, providing accurate measurement of competencies, flexibility in time and place, immediate feedback and scoring, and advanced results analysis (Hoogland \& Tout, 2018; Lin \& Lai, 2019; Shute \& Rahimi, 2016).

In the spirit of embracing differentiated alternative assessment and optimizing students' mixed-ability, the researchers have designed and developed a generic web-based tool named PutraPacer that allows instructors to create differentiated assessments. PutraPacer provides tiered levels of assessments that are appropriate for varied types of students, such that they can demonstrate that they have learned, regardless of, and according to, their ability. With its customizable function, PutraPacer is developed to fill the voids in 


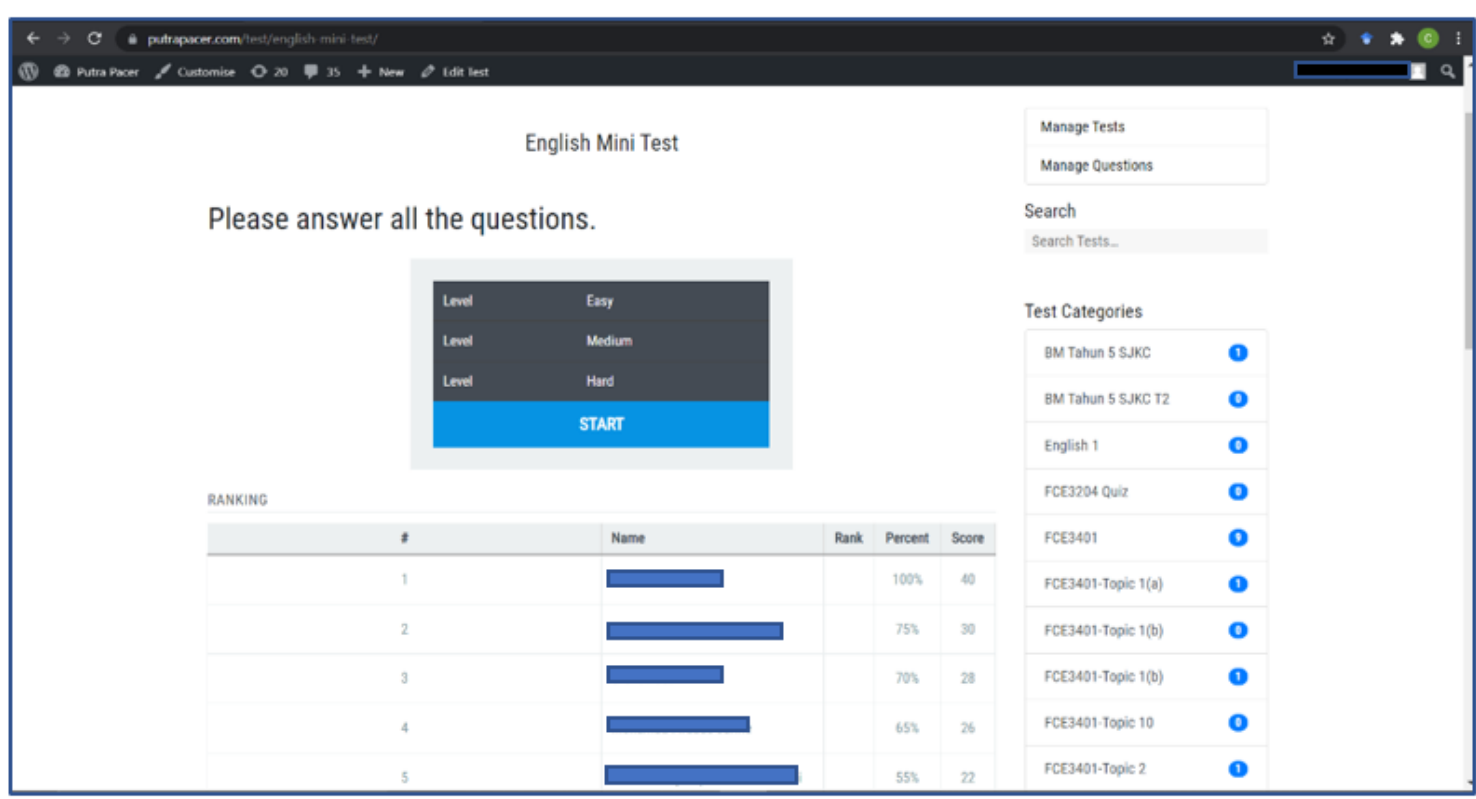

Figure 1. A multi-tiered test

examination-driven education as it enables educators who do not have the pedagogical know-hows of differentiated assessment to implement this approach with their students. As a generic web-based tool, PutraPacer can be employed to any subject and education level.

PutraPacer borrows the elements of differentiated instruction, which provides choice and opportunities for students to get appropriate education in general education classrooms (Lawrence-Brown, 2004). As compared to traditional assessment or tests, differentiated assessment can benefit students ranging from gifted to those with significant disabilities by providing tiered or multi-level assessment system that will adapt to students' answers and responses. For instance, instructors could create a quiz with tiered levels of assessments based on different levels level of difficulty like easy, medium, and hard (Figure 1). Students can only advance to the next level of difficulty if they manage to accomplish the goal of the level they are currently at. The goal refers to a pass mark which is determined by the instructor. For example, if the students managed to achieve the pass mark for the 'easy' level, they could proceed to answer questions at the 'medium' level. Otherwise, if they are not able to advance to the next level, they can continue to answer subsequent questions offered at their current level.

Another distinct feature of PutraPacer as a differentiated assessment tool is its capacity to provide a platform for students to demonstrate what they have learned according to their niche abilities and interests. Instructors could create questions that prompt students to submit or present their answers in various ways such as mind maps, audio recording or video recording (Figure 2). This feature was developed based on the theory of Multiple Intelligence by Gardner (1983). He asserts that people process the world and demonstrate their strengths in multiple ways, and intelligence can be constructed and achieved with non-conventional methods (Crim et al., 2013). Besides that, in the context of assessment, Gardner (1992) believes that assessments that fail to address differences among individuals are outdated.

Vygotsky's (1999) theory of Zone of Proximal Development (ZPD) is fundamental in foregrounding the concept of differentiation in the development of PutraPacer. According to Tomlinson and Moon (2013), within the ZPD, learning happens "on a novice-to-expert continuum that builds over time rather than being constrained by a specific set of grade-level standards" (p. 72). The ZPD concept, which is also seen as a scaffolding enables students to accomplish tasks which at first beyond their capabilities (Wood et al., 1976). Scaffolding is found to help develop students' abilities by increasing the complexity levels of a task and revealing their hidden potential (Ajideh \& Nourdad, 2012; Shabani et al., 2010). 


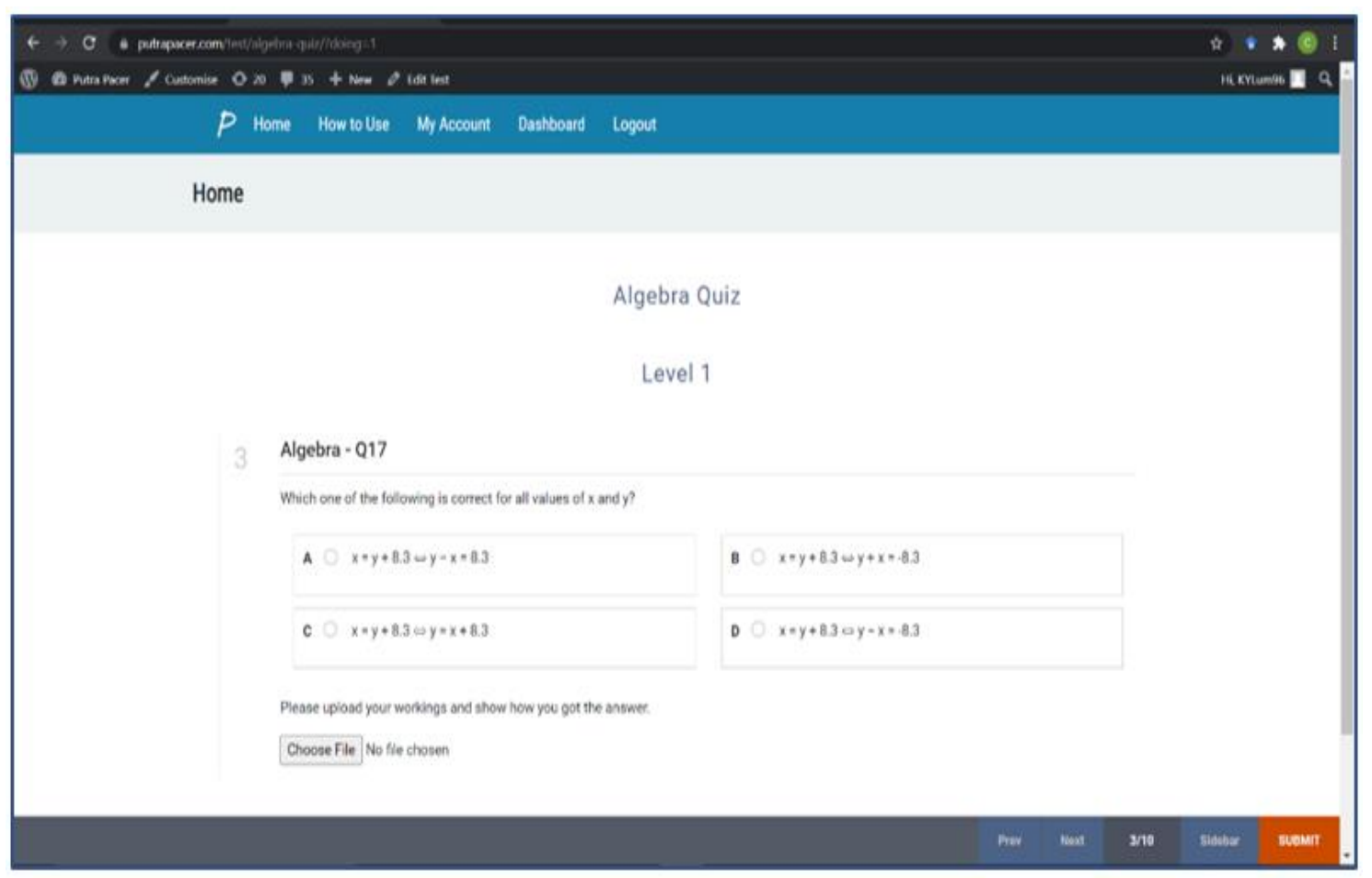

Figure 2. Students could attach a file to present their answer in alternative form

PutraPacer aims to provide flexibility to ease the pressure on middle to low ability learners to genuinely learn and engage in depth with their learning instead of memorizing the information (Llewellyn, 2002), as well as benefit advanced leaners with the opportunities to engage in a more challenging and higher order thinking skills tasks. This will, in return, provide a much accurate insight of students' skills and abilities (Dikli, 2003).

The prototype of the assessment tool was employed on a group of undergraduate students at Universiti Putra Malaysia to assess its' usability and functionality. The central focus of this study is therefore to elicit learners' feedback and perspective on the use of PutraPacer as a differentiated assessment tool.

\section{THEORETICAL FRAMEWORK}

The Unified Theory of Acceptance and Use of Technology (UTAUT) was optimized as the lens of this study. Students' feedback on the use of PutraPacer as a differentiated assessment tool were elicited both quantitatively and qualitatively through survey questionnaires and one-to-one semi-structured interviews. Many research studies on computer-based assessments utilize UTAUT as it is regarded as a comprehensive framework for its high explanatory power. It has also been successfully applied to establish studies in various educational context (Lawson-Body, 2018; Suki \& Suki, 2017). Based on the UTAUT model, intention or usage is significantly determined by four constructs namely, performance expectancy, effort expectancy, social factors, and facilitating conditions (Venkatesh et al., 2003). Generally, in this study, 'performance expectancy' refers to the degree to which the students believe that PutraPacer helps them in their learning and eventually improve their performance in their studies. 'Effort expectancy' is the degree of ease related to the use of PutraPacer as a differentiated assessment tool. Meanwhile, 'social influence' means the degree to which the students believe they should use PutraPacer based on influence of people like classmates and lecturers, and also environment like the university itself. 'Behavioural intention to use' reflects the degree to which the students intend to use PutraPacer for their studies in the future. The construct 'facilitation conditions' was not measured as PutraPacer was employed as obligatory assessments for students who were enrolled in a course which they enrolled during the time of the study. 


\section{METHODS}

This study employs an explanatory sequential mixed methods design. This involves the first phase where quantitative data was collected through questionnaire surveys followed by the second phase where qualitative data was gathered through observation and interviews. By employing the explanatory sequential mixed methods design, the results from the quantitative data could provide general insights of the research problem while the qualitative data could help explain on the quantitative results (Creswell, 2012).

\section{Participants and Context}

This pilot study took place in one of the local public universities in Selangor, Malaysia. A total of 32 undergraduate students taking courses under the Faculty of Computer Science and Information Technology, and Faculty of Educational Studies responded to a questionnaire. According to Whitehead et al. (2016), a reasonable sample size of at least 30 or greater is preferable for a pilot study. However, Johanson and Brooks (2009) pointed out that a sample size that range from 10 to 15 is good enough in providing for pilot study. The researcher decided to distribute the questionnaire to 32 respondents in order to obtain adequate data to make up for possible missing respondents and nonresponses which will affect the study's aim to check the instrument used as well as the findings. Observation was carried out in one of the Multimedia Laboratory sessions for undergraduate students at the Faculty of Computer Science and Technology. Two students, Ahmad and Nur, were interviewed after the session. These participants were students whose course instructors volunteered to employ PutraPacer for assessments in their class. All participants had to answer quiz or test questions on PutraPacer before they complete the questionnaire or were interviewed. To safeguard the participants, pseudonyms are used in presenting the findings.

\section{Procedure}

Prior to data collection, course instructors were recruited through a series of training workshops on how to utilise PutraPacer for differentiated assessment. To supplement the trainings, video tutorials and a 'how-to' module were also provided. Other than that, the course instructors could contact the researchers or the developer of PutraPacer for assistance. After the trainings, two course instructors volunteered to participate in the pilot study. These course instructors are experts in Human-Computer Interaction and Economic Education respectively and have more than five years of teaching experience. Both of them managed to conduct two taxonomy-based assessments using PutraPacer before data collection for the pilot study began.

\section{Data Collection}

In the first phase of data collection, a questionnaire with thirty items was distributed and collected online using Google Forms. These items were adopted from Ibrahim et al. (2016) work which are based on the UTAUT model by Venkatesh et al. (2003). Based on Cronbach'S alpha coefficient test, the reliability of all constructs in their study exceeded .70. Thus, all constructs were acceptable (Hair et al., 2020). The questionnaire comprises four constructs namely performance expectancy, effort expectancy, social influence, and behavioural intention to use with the total of 30 items. Each construct was measured through five-point Likert-scale ranging from 1 (strongly disagree) to 5 (strongly agree).

The second phase of data collection involved observation and interviews. First, the researcher attended a Multimedia Laboratory session, a class of eighteen first-year undergraduate students with a course instructor. During this session, a non-participatory observation was conducted focusing on how the students responded to quiz questions that was done online via PutraPacer. Field notes were taken during this observation. After the quiz session was over, a semi-structured interview was carried out with two volunteering students. The interviews which lasted for about 40 minutes each were done to draw their feedback on their experiences in using PutraPacer. To demonstrate validity and credibility of the qualitative research methods, the researchers adopted approaches like trustworthiness and triangulation. The use of experts validated interview protocol (Appendix A) in this study add value of trustworthiness (Yin, 2016). Meanwhile, triangulation of data sources where data were collected from multiple sources such as observation and interviews, add credibility to the study (Patton, 2015). 
Table 1. TitleHere

\begin{tabular}{lcc}
\hline Constructs & Number of items & Cronbach's alpha \\
\hline Performance expectancy & 9 & .987 \\
Effort expectancy & 10 & .975 \\
Social influence & 6 & .977 \\
Behavioural intention to use & 5 & .979 \\
\hline
\end{tabular}

Table 2. Descriptive statistic for performance expectancy construct

\begin{tabular}{lcc}
\hline Performance expectancy & Mean & SD \\
\hline I think PutraPacer is helpful for my learning. & 3.72 & 1.32 \\
Using PutraPacer improves my engagement with learning. & 3.69 & 1.25 \\
Using PutraPacer as an assessment tool improves my performance in my study. & 3.59 & 1.24 \\
Using PutraPacer for revision saves me a lot of time. & 3.53 & 1.29 \\
PutraPacer helps me to become an independent learner. & 3.56 \\
PutraPacer helps me to become an autonomous learner. & 3.44 \\
PutraPacer offers me the flexibility to learn. & 3.63 & 1.19 \\
PutraPacer is an assessment tool that helps scaffold my learning. & 3.50 & 1.24 \\
Overall, I would find that the usage of PutraPacer brings advantages for learning purposes. & 3.69 & 1.24 \\
Overall & $\mathbf{3 . 5 9}$ & $\mathbf{1 . 2 6}$ \\
\hline
\end{tabular}

\section{Data Analysis}

For the quantitative component, reliability analysis, descriptive statistical analysis \& correlation analysis was used to analyse the data with Statistical Package for the Social Science (SPSS) Statistics version 22 software. The analyses aim to obtain richer understanding of the students' perspective based on the UTAUT model.

A reliability test was conducted using Cronbach's alpha coefficient to measure the consistency and stability of the instrument used for quantitative data (Cronbach, 1951). The questionnaire items were analysed using SPSS software. As summarized in Table 1, the range of Cronbach's alpha for all constructs were more than 0.90 which are preferable (Pallant, 2016). The findings of the reliability study reveal that all four constructs are valid and reliable in terms of students' perceptions of PutraPacer measurement. This is due to the fact that the questionnaire items were taken from a previously conducted study that had been empirically tested and conceptualised.

Meanwhile, the two-cycle data analysis adopted from Saldaña (2009) was employed for the qualitative component. In the first cycle, after the field notes and interview transcripts were read and re-read to increase the researcher's familiarity with the data, the data were coded using in Vivo Coding and Descriptive Coding with memos. Next, in the second cycle, Pattern Coding is used with memos-on-memos to develop major categories from the data. The qualitative data analysis was finalized by regrouping the categories to form coherent themes. To retain both the emic perspective of the participants, and the etic perspective of the researchers and theory, a constant comparative method was employed for qualitative data analysis (Charmaz, 2014, p. 53)

\section{FINDINGS}

\section{Quantitative Data}

This section discusses the descriptive statistical analysis (performance expectancy, effort expectancy, social influences, and behavioural intention to use) and the relationship between the constructs used in this study.

\section{Performance expectancy}

Table 2 summarizes students' perspective on performance expectancy. There are nine items in this construct with overall mean $3.59(\mathrm{SD}=1.26)$. The highest mean refers to students' perception that using PutraPacer is 
Table 3. Descriptive statistic for effort expectancy constructs

\begin{tabular}{lcc}
\hline Effort expectancy & Mean & SD \\
\hline As an online assessment tool, PutraPacer is easy to use. & 3.88 & 1.26 \\
PutraPacer is a convenient tool for assessment (e.g quiz, test, and exam). & 3.66 & 1.26 \\
PutraPacer is very accessible. & 3.75 & 1.32 \\
As a user, having a minimal competency in computer skills is sufficient to use PutraPacer. & 3.72 & 1.30 \\
Learning to use PutraPacer is easy for me. & 3.84 \\
I need more time to get familiar with PutraPacer then I expected. & 3.13 \\
The instructions on how to use PutraPacer by my lecturer is helpful. & 3.91 \\
More instruction is needed on how to use PutraPacer. & 3.47 \\
The technical part of using PutraPacer did not affect how I answer the quiz/test/exam. & 3.59 \\
Overall, I find PutraPacer is user friendly. & 3.78 \\
Overall & $\mathbf{3 . 6 7}$ & 1.35 \\
\hline
\end{tabular}

Table 4. Descriptive statistic for social influences construct

\begin{tabular}{lcc}
\hline Social influences & Mean & SD \\
\hline My classmates think that I should use PutraPacer to help me do my revision. & 3.19 & 1.23 \\
My lecturer is very supportive in using PutraPacer for learning. & 3.88 & 1.21 \\
In general, the university supported the use of online assessment for learning. & 3.78 & 1.29 \\
PutraPacer should be used widely in the university. & 3.75 & 1.30 \\
My classmates have influenced me a lot in using PutraPacer for learning. & 3.41 & 1.29 \\
I would use PutraPacer for learning because my classmates are also using it. & 3.53 & 1.30 \\
Overall & $\mathbf{3 . 5 9}$ & $\mathbf{1 . 2 7}$ \\
\hline
\end{tabular}

helpful for their learning (Mean=3.72, SD=1.32) while the lowest mean in this construct refers to the perception that PutraPacer helps the students to become an autonomous learner (Mean=3.44, SD=1.24).

\section{Effort expectancy}

Findings in Table 3 indicates the students' perspective on effort expectancy. This construct consists of ten items with overall mean $3.67(S D=1.34)$. The highest mean in this construct refers to how instructions given by the lecturers are helpful in using PutraPacer (Mean=3.91, SD=1.35). The lowest mean indicates that respondents needed more time than expected to get familiar with PutraPacer (Mean=3.13, SD=1.56).

\section{Social influence}

Table 4 shows the students' perspective on social influence. Six items made up this construct with overall mean 3.59 ( $S D=1.27$ ). More than $50 \%$ of the respondents either agree or strongly agree on all the statements except for one item where only $40.6 \%$ of the respondents either agree or strongly agree that there were influences from their classmates in regards of using PutraPacer for revision. The highest mean in this construct refers to lecturer's support in using PutraPacer for learning (Mean=3.88, SD=1.21) while the lowest mean which is $3.19(S D=1.23)$ refers to the perception of the respondents' classmates in regards of using PutraPacer for revision.

\section{Behavioural intention to use}

Table 5 presents the findings on the students' perspective on behavioural intention to use. There are five items in this construct with overall mean $3.56(S D=1.21)$. The highest mean in this construct refers to two items where students believe that PutraPacer will be a basis for future online alternative assessment (Mean=3.72, SD=1.20) and they look forward to use PutraPacer for learning in the future (Mean=3.72, $S D=1.22)$. On the other hand, the lowest mean refers to students' intention to continue doing their revision through assessments in PutraPacer (Mean=3.41, SD=1.27). 
Table 5. Descriptive statistic for behavioural intention to use construct

\begin{tabular}{lcc}
\hline Behavioural intention to use & Mean & SD \\
\hline I will continue to do my revision through assessments in PutraPacer. & 3.41 & 1.27 \\
I will continue to use PutraPacer to improve my learning skills. & 3.44 & 1.24 \\
I intend to support the continuous use of PutraPacer as an assessment tool for my course. & 3.53 & 1.14 \\
I think the differentiation feature (e.g., level-based question) in PutraPacer will be a basis & 3.72 & 1.20 \\
for future online alternative assessment. & 3.72 \\
I look forward to more opportunity to use PutraPacer for learning in the future. & $\mathbf{3 . 5 6}$ & 1.22 \\
Overall & $\mathbf{1 . 2 1}$ \\
\hline
\end{tabular}

Table 6. Pearson correlations between performance expectancy, effort expectancy, social influence, and behavioural intention to use

\begin{tabular}{|c|c|c|c|c|}
\hline & 1 & 2 & 3 & 4 \\
\hline Performance expectancy & - & & & \\
\hline Effort expectancy & $.955^{* *}$ & - & & \\
\hline Social influence & $.951 * *$ & $.937^{* *}$ & - & \\
\hline Behavioural intention to use & $.958 * *$ & $.956 * *$ & $.953 * *$ & - \\
\hline
\end{tabular}

**Correlation is significant at the 0.01 level (2-tailed)

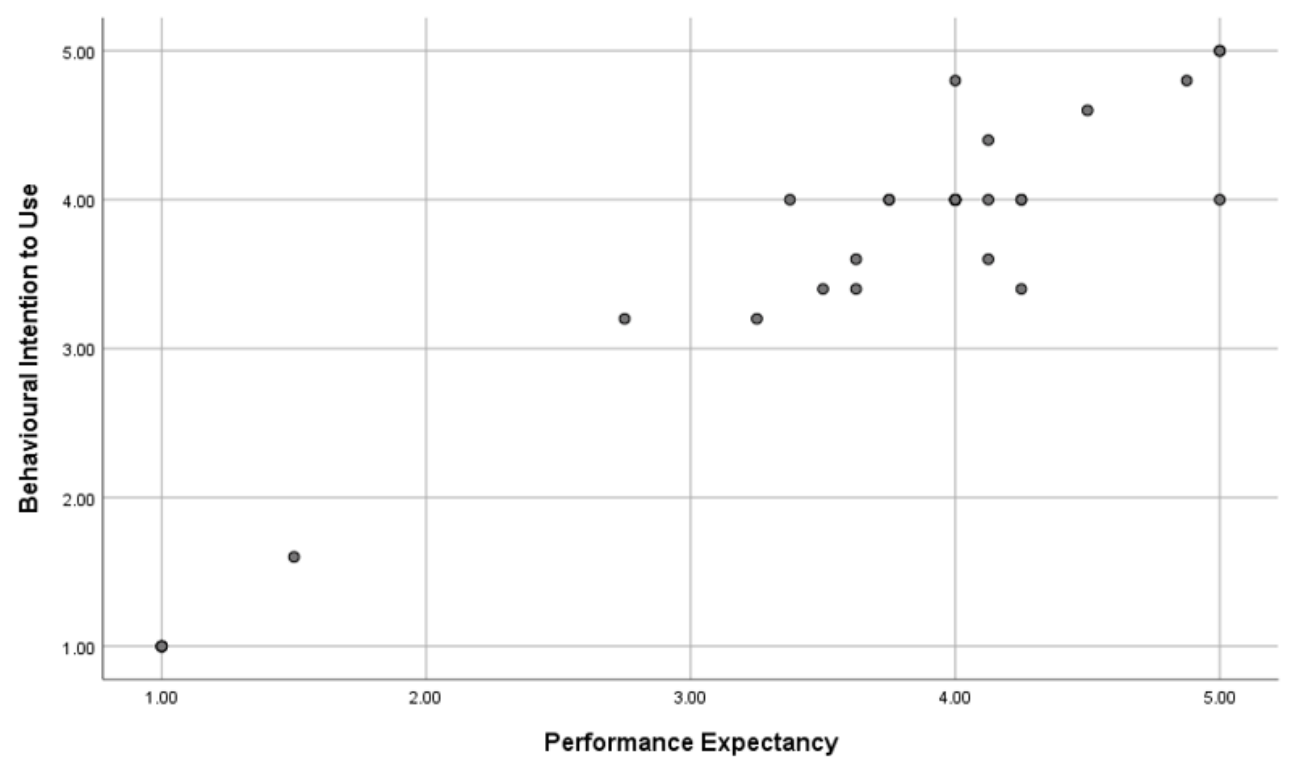

Figure 3. Linear relationship between the performance expectancy and behavioural intention to use

PutraPacer

\section{Pearson correlations}

Table 6 provides a summary of a Pearson correlation analysis to test the relationships the relationship between performance expectancy (PE), effort expectancy (EE), social influence (SI) and behavioral intention to use (BI).

Based on the findings, the value of Pearson's correlation $r=0.958$ ( $P E$ and $\mathrm{BI}), r=0.956(\mathrm{EE}$ and $\mathrm{BI})$, and $r=0.953$ (SI and $\mathrm{BI}$ ) show that there are strong positive relationships between performance expectancy, effort expectancy, and social influence with behavioural intention to use PutraPacer. The higher of performance expectancy, effort expectancy and social influence among the students, the higher behavioural intention to use PutraPacer will be.

Figure 3, Figure 4, and Figure 5 show the linear relationship between the performance expectancy, effort expectancy, and social influence with behavioural intention to use PutraPacer, respectively. 


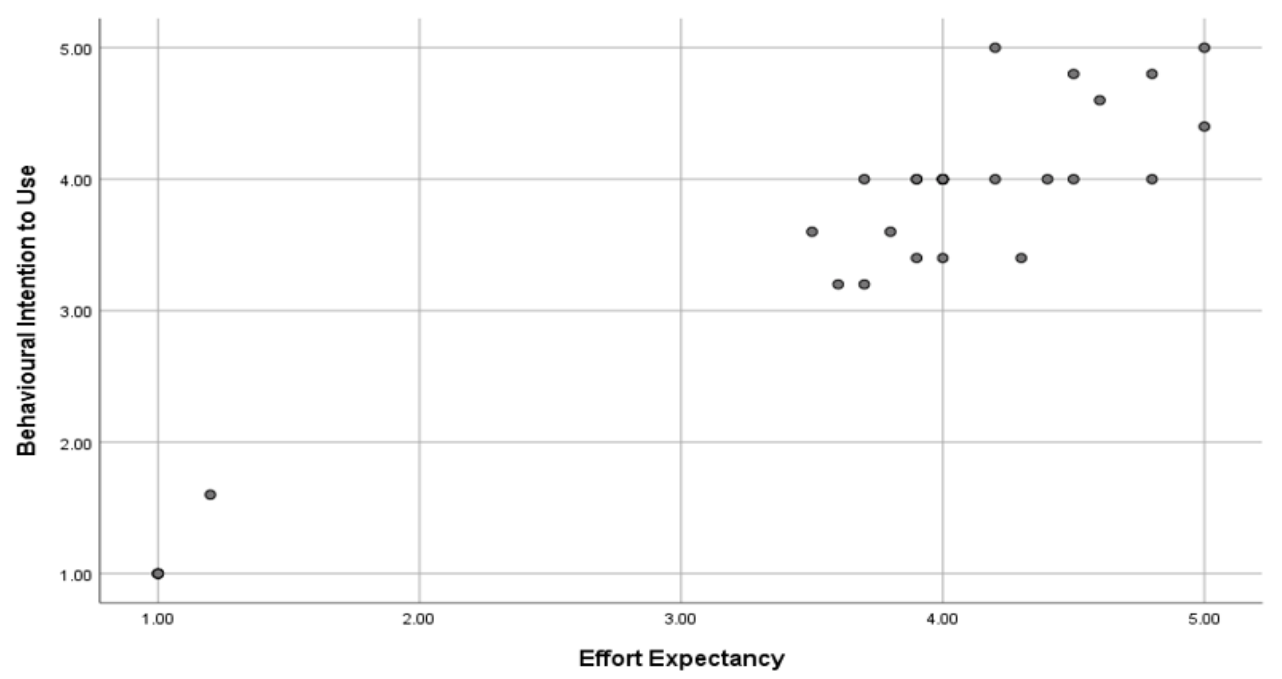

Figure 4. Linear relationship between effort expectancy and behavioural intention to use PutraPacer

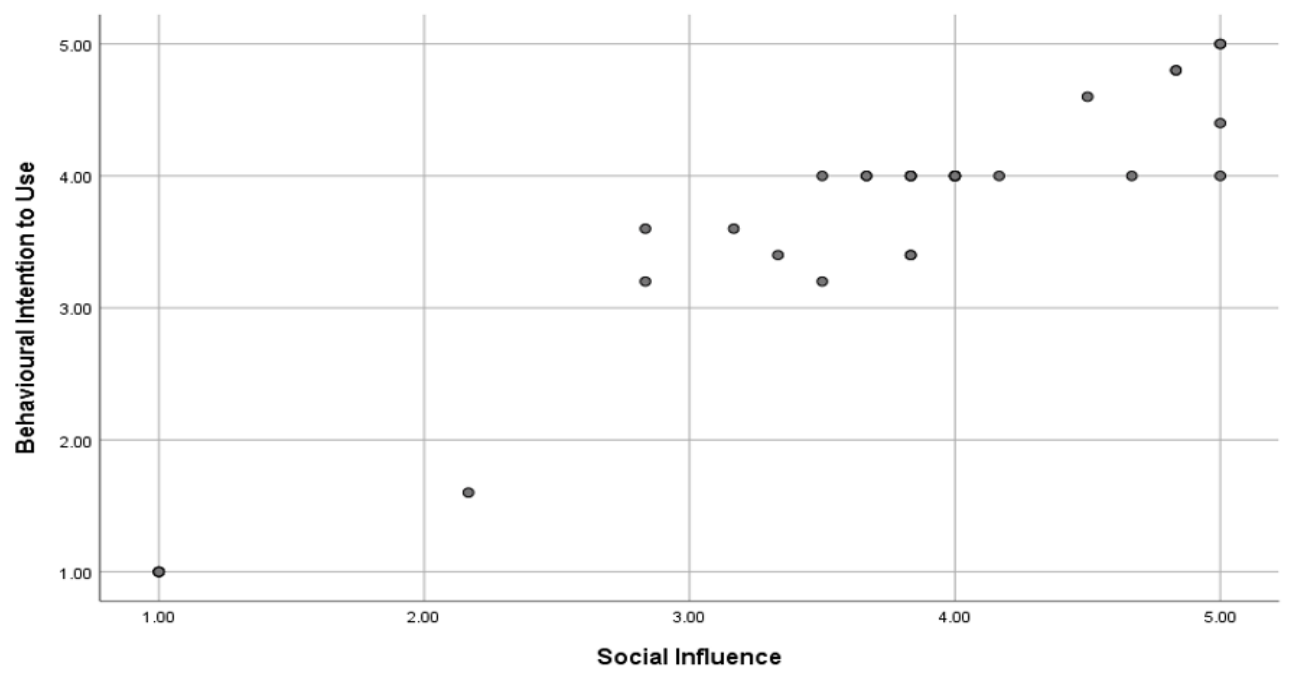

Figure 5. Linear relationship between social influence and behavioural intention to use PutraPacer

\section{Qualitative Data}

Three themes emerged from the interviews and observation analysis, namely, PutraPacer:

1. is user-friendly,

2. promotes individualised learning experience and supports students with different abilities, and

3. functions as a platform for practices, quizzes, and revision.

\section{PutraPacer is user-friendly}

The interviewed participants, Ahmad and Nur, showed positive feedback on their experience in using PutraPacer to answer quiz questions. Based on their expression, both indicated that using PutraPacer for assessment is enjoyable.

It felt good. It felt very natural and intuitive for the most part...I would say just the general layout felt very clean very nice. It didn't have many...it felt very easy to go through from question to question and it was laid out really pleasingly (Ahmad). 
I actually really enjoyed the experience because, well to compare with my previous experience with PutraBlast quiz, I prefer PutraPacer more because it's easier, it's very user-friendly and I really like the design of it (Nur).

Based on observation, the researcher noticed that the quiz session was conducted in a laid-back manner. The session was smooth, though occasionally, some students asked for help on the technical settings of PutraPacer such as login and navigating the pages. In a casual discussion, when the instructor asked how the students think of the assessment, a couple of students responded that they were being competitive with each other because the quiz looks like an online game as they need to achieve a certain score to advance to the next level.

\section{PutraPacer promotes individualised learning experience and supports students with different abilities}

Based on her experience sitting for assessments in written and digital forms before, Nur believed that PutraPacer is different as it offers individualised learning experience. In addition to that, Ahmad and Nur agreed that PutraPacer can support students with different ability in a way that students became more aware of their own ability.

....t's more individual and you can test your ability to know how much you know about the subject...we can know which level we are at (Nur).

From my thoughts, it seems to allow different types of people to be able to engage with the same quiz whereas in the standard quiz, we have both hard and easy questions at once which isn't really suited for people who aren't as advance (Ahmad).

As observed by the researcher, during the quiz session, the students did the quiz at their own pace. Although the questions given were the same for all the students, the questions did not appear in the same order as they were randomly ordered. This feature encourages students to think on their own as they had to focus on their own set of questions. Some of the students also made the effort to self-review the questions which they had answered wrongly and discuss it with the instructor.

\section{PutraPacer as a good platform for practices, quizzes, and revision}

To some extent, Ahmad and Nur support the use of PutraPacer as a differentiated assessment tool.

I would [support]. It seems like a very good platform from what I have used of it. I think its use could be expanded as it is a good tool for students and teachers alike (Ahmad).

For test, maybe not. For quizzes, yes. For in class, for practice and revision... Because, it has levels, right? (Nur).

These findings suggest that students are looking forward to other types of examination and the use of PutraPacer is well received as a tool for differentiated assessment. They were also ready to move away from the practise of standardized test and ready to embrace assessments.

\section{DISCUSSION}

This pilot study aims to explore students' perspectives on the use of PutraPacer as a differentiated assessment tool based on the UTAUT theory, namely performance expectancy, effort expectancy, social influence, and behavioural intention to use. One of the constructs from UTAUT, which is facilitating condition, was not measured because PutraPacer was used as an obligatory assessment in the course.

Results from the quantitative data reveals that in terms of performance expectancy, most of the students perceived that PutraPacer brings advantages for learning purposes. The value of Pearson's correlation coefficient, $r=0.956$ (Table 6 ), shows that there is a strong positive relationship between effort expectancy and behavioural intention to use. In other words, the higher effort expectancy among students, the higher 
behavioural intention to use PutraPacer will be. As claimed by Lin and Lai (2019), performance expectancy demonstrates the degree where students believe that a system can assist them to improve their academic performance. Therefore, this finding indicates that PutraPacer has the potential to be used to enhance students' learning. Findings from the qualitative data further supports this statement whereby positive learning experiences are gained by the students. Based on the interviews, the students suggested that the quiz that they did was individualized and at the end of the quiz, they were aware of their own level of ability. This show that PutraPacer managed to integrate the element of differentiation, where students are provided with opportunities to get proper education in the context of general education classrooms by learning according to their own abilities (Lawrence-Brown, 2004). Through such differentiation, there will be less pressure on learning especially among the low to middle ability learners as they are able to focus on the learning instead of memorizing the information. Meanwhile, for advance learners, they will have the opportunities to assume more challenging tasks (Llewellyn, 2003). This finding resonates the concept of giving achievable tasks that are appropriate for students' level of abilities and not bounded by a rigid timeline could build students' mastery and prepare them to higher-level tasks (Moon et al., 2020). Moon et al. (2020) asserted, tasks that are too difficult for students are detrimental to their learning progress while giving them tasks that are not challenging is deemed as "a lost learning opportunity" (p. 34). As implied by one of the students during the interview, using PutraPacer gave her the sense of individualised learning. Individualised learning like completing a given task at students own pace enables students to improve their level of ability (Ali, 2015; Ajideh \& Nourdad, 2012).

In terms of effort expectancy, it is found that most of the students agree or strongly agree that PutraPacer is easy to use. User-friendly technology is closely related to the term 'effort expectancy' which Venkatesh et al. (2003) defined as the level of easiness when using any system. Effort expectancy is also believed to significantly influence users' intention to use a technology (Venkatesh et al., 2003). This finding is important to determine the effectiveness of PutraPacer as a computer-based assessment tool and whether it can easily be accepted and adopted by users (Catherine et al., 2017; Lin \& Lai, 2019). Based on the interview, both students agree that PutraPacer is easy to use. This consolidates the quantitative finding. As a formative assessment tool, being user-friendly is a trait that could support effective feedback (Tomlinson \& Moon, 2013). According to Moon et al. (2020), feedback helps students to understand the purpose of learning goals which consequently gives them opportunities to reach the goals. On the same note, while agreeing that PutraPacer is user-friendly, these students also expressed their enjoyment when using PutraPacer during the quiz. It was apparent that during the observation, the researcher noticed that during the lab session in which the quiz was conducted, the students seemed not pressured by the fact that they were doing an assessment. This denotes a positive finding which is consistent with Hashemian (2011) who emphasises that learning without pressure could leads to creativity, besides creating awareness and giving learning satisfaction among students. Earlier study by Isen et al. (1987) also believe that positive effects play a role in facilitating creative problem-solving which is now considered as one of the essential skills in the $21^{\text {st }}$ century education (Alias \& Osman, 2015; Burke, 2005).

In terms of social influence, the quantitative results revealed that majority of the students perceived that in one way or another, their classmates, lecturer, and the university environment had influenced their use of PutraPacer. Based on observation, the researcher noted that there are some attributes of competitiveness shown among the students. Although Moon et al. (2020) disagree on emphasizing competition among students especially when striving for a "socially relevant classroom" (p. 37), some studies suggest that competitive behaviour is a trait of people who are most likely to succeed (Baumann \& Harvey, 2018) and the capability of an instructor has a more significant effect on learners' motivation and performance (Nguyen \& Nguyen, 2010).

Based on the quantitative data, the mean values for performance expectancy, effort expectancy, social influences, and behavioural intention to use ranged between 3.56 and 3.67. The highest construct is effort expectancy (Mean=3.67) while performance expectancy and social influences generated similar mean values (Mean=3.59). Findings from the interview also indicated that students support the use of PutraPacer to some extent. This implies that that most of the students have the intention to use PutraPacer in the future 
especially if it were used for practices, quizzes, and revisions due to its level-based feature. This view echoed the same sentiment with Noguera (2015) who believes that it is more beneficial for students when they are given sufficient opportunities to advance to next level based on demonstrations of their content knowledge and skills. A one-off graded test might not be helpful in this context. These arguments also show consistency with the idea of conducting formative assessments in a differentiated classroom (Moon et al., 2020). Moon et al. (2020) believe that formative assessments should not be graded since this is when students learn to master the content of a topic or a lesson, and data from these assessments will be used by the instructors for instructional planning. Nevertheless, PutraPacer can be potentially used to administer formative and summative assessments. These findings are important to guide instructors on the direction of their instructional plan especially when they are considering using PutraPacer as an assessment tool.

\section{CONCLUSIONS}

In sum, the findings from the pilot study suggested that most of the students who took part of this study perceived that the use of PutraPacer has positive effects on their learning. Besides enriching their individual learning experience, PutraPacer also shows its capacity to address learners' diverse abilities. PutraPacer is easy to use, and students enjoyed using it. This pilot study presents some limitations. First, the number of participants for the interview is too small. However, the data from the interviews provide insights on how the features in PutraPacer can be improved. Secondly, since a part of this study is qualitative in nature, the findings are not meant for generalization. Therefore, the findings can only be applied to classes with almost similar characteristics. Although PutraPacer is deemed as a good platform for differentiated assessment, there is still room for improvement especially in the idealisation of equal opportunity in learning. This study welcomes further research, whether quantitative or qualitative in nature, to explore how a differentiated assessment tool could address learners' individual needs while at the same time providing them with unlimited access to learning resources regardless of their proficiency levels.

Author contributions: All authors were involved in concept, design, collection of data, interpretation, writing, and critically revising the article. All authors approve final version of the article.

Funding: This work was supported by the Centre for Academic Development, Universiti Putra Malaysia via the Incentive for Teaching and Learning Grant (GIPP 9323753).

Declaration of interest: Authors declare no competing interest.

Data availability: Data generated or analysed during this study are available from the authors on request.

\section{REFERENCES}

Adnan, N. L., Mohd Sallem, N. R., Muda, R., \& Wan Abdullah, W. K. (2019). Is current formative assessment still relevant in turning students into deep learners? TEM Journal, 8(1), 298-304. https://doi.org/10. 18421/TEM81-41

Ajideh, P., \& Nourdad, N. (2012). The effect of dynamic assessment on EFL reading comprehension in different proficiency levels. Language Testing in Asia, 2(4), 101-122. https://doi.org/10.1186/22290443-2-4-101

Algozzine, B., \& Anderson, K. M. (2007). Tips for teaching: Differentiating instruction to include all students. Preventing School Failure: Alternative Education for Children and Youth, 51(3), 49-54. https://doi.org/ 10.3200/psfl.51.3.49-54

Ali, H. I. H. (2015). Toward differentiated assessment in a public college in Oman. English Language Teaching, 8(12), 27-36. https://doi.org/10.5539/elt.v8n12p27

Alias, A., \& Osman, K. (2015). Assessing oral communication skills in science: A rubric development. Asia Pacific Journal of Educators and Education, 30, 107-122. http://eprints.usm.my/34769/1/ APJEE_30_Art_7_(105_-_122).pdf 
Al-Mahrooqi, R., \& Denman, C. (2018). Alternative assessment. In J. I. Liontas \& M. DelliCarpini (Eds.), The TESOL encyclopedia of English language teaching (pp. 1-6). John Wiley \& Sons, Inc. https://doi.org/ 10.1002/9781118784235.eelt0325

Anggraeni, C. W. (2018). Promoting education 4.0 in English for survival class: What are the challenges? The Journal of English Language and Literature, 2(1), 12-24. https://doi.org/10.31002/metathesis.v2i1.676

Baumann, C., \& Harvey, M. (2018). Competitiveness vis-à-vis motivation and personality as drivers of academic performance. International Journal of Educational Management, 32(1), 185-202. https://doi.org/10.1108/IJEM-10-2017-0263

Black, P., \& Wiliam, D. (1998). Assessment and classroom learning. Assessment in Education: Principles, Policy \& Practice, 5(1), 7-74. https://doi.org/10.1080/0969595980050102

Burke, K. (2005). How to assess authentic learning (4th ed.). Corwin Press.

Caliskan, H. \& Kasikci, Y. (2010). The application of traditional and alternative assessment and evaluation tools by teachers in social studies. Procedia Social and Behavioural Sciences, 2(2010), 4152-4156. https://doi.org/10.1016/j.sbspro.2010.03.656

Catherine, N., Geofrey, K. M., Moya, M. B., \& Aballo, G. (2017). Effort expectancy, performance expectancy, social influence and facilitating conditions as predictors of behavioural intentions to use ATMs with fingerprint authentication in Ugandan banks. Global Journal of Computer Science and Technology: $E$ Network, Web \& Security, 17(5), 5-22. https://computerresearch.org/index.php/computer/article/ view/1622

Chan, T. W., Looi, C. K., Chen, W., Wong, L. H., Chang, B., Liao, C. C. Y., Cheng, H., Chen, Z. H., Liu, C.C., Kong, S.C., Jeong, H., Mason, J., So, H. J., Murthy, S., Yu, F. Y., Wong, S.L., King, R. B., Gu, X., Wang, M., ... Ogata, H. (2018). Interest-driven creator theory: Towards a theory of learning design for Asia in the twenty-first century. Journal of Computers in Education, 5, 435-461. https://doi.org/10.1007/s40692018-0122-0

Chan, Y. F., \& Sidhu, G. K. (2010). Authentic assessment and pedagogical strategies in higher education. Journal of Social Sciences, 6(2), 153-161. https://doi.org/10.3844/jssp.2010.153.161

Charmaz, K. (2014). Constructing grounded theory. SAGE.

Chin, H., Thien, L. M., \& Chew, C. M. (2019). The reforms of national assessments in Malaysian education system. Journal of Nusantara Studies, 4(1), 93-111. https://doi.org/10.24200/jonus.vol4iss1pp93-111

Creswell, J. W. (2012). Educational research: Planning, conducting, and evaluating quantitative and qualitative research (4th ed.). Pearson Education, Inc.

Cronbach, L. J. (1951). Coefficient alpha and the internal structure of tests. Psychometrika 16(3), 297-334. https://doi.org/10.1007/BF02310555

Dikli, S. (2003). Assessment at a distance: Traditional vs. alternative assessments. The Turkish Online Journal of Educational Technology, 2(3), 13-19. https://files.eric.ed.gov/fulltext/EJ1101956.pdf

Fisk, P. (2017). Education 4.0 ... the future of learning will be dramatically different, in school and throughout life. https://www.peterfisk.com/2017/01/future-education-young-everyone-taught-together/

Gardner, H. (1992). Assessment in context: The alternative to standardized testing. In B. R. Gifford \& M. C. O'Connor (Eds.), Changing assessments: Alternative views of aptitude, achievement, and instruction (pp. 77-119). Springer. https://doi.org/10.1007/978-94-011-2968-8_4

Ghani, I. B. A., Ibrahim, N. H., Yahaya, N. A., \& Surif, J. (2017). Enhancing students' HOTS in laboratory educational activity by using concept map as an alternative assessment tool. Chemistry Education Research and Practice, 18(4), 849-874. https://doi.org/10.1039/C7RP00120G 
Gozuyesil, E., \& Tanriseven, I. (2017). A meta-analysis of the effectiveness of alternative assessment techniques. Eurasian Journal of Educational Research, 70, 37-56. https://doi.org/10.14689/ejer.2017. 70.3

Gregory, G. H., \& Chapman, C. (2013). Differentiated instructional strategies: One size doesn't fit all. Corwin Press.

Gulicheva, E., Lisin, E., Osipova, M., \& Khabdullin, A. (2017). Leading factors in the formation of innovative education environment. Journal of International Studies, 10(2), 129-137. https://doi.org/10.14254/ 2071-8330.2017/10-2/9

Hariharasudan, A., \& Kot, S. (2018). A scoping review on digital English and education 4.0 for industry 4.0. Social Sciences, 7(11), 227. https://doi.org/10.3390/socsci7110227

Hashemian, M., \& Azadi, G. (2011). Arguing for the use of portfolio in L2 classrooms. Theory and Practice in Language Studies, 1(5), 501-506. https://doi.org/10.4304/tpls.1.5.501-506

Ho, E., Bin, J., \& Chang, J. (2012). Survey of middle school student learning: Saving the generation of unmotivated. http://topic. parenting.com.tw/issue/2013/futurelearning/article2-1-2.aspx

Hoogland, K., \& Tout, D. (2018). Computer-based assessment of mathematics into the twenty-first century: Pressures and tensions. ZDM, 50(4), 675-686. https://doi.org/10.1007/s11858-018-0944-2

Ibrahim, N., Mohd Ayub, A. F., \& Md. Khambari, M. N. (2016, December 17). Students'perspectives on the use of mobile phone in learning activities [Paper presentation]. Graduate Research in Education (GREduc) 2016 Seminar, Selangor, Malaysia. http://spel3.upm.edu.my/max/dokumen/ GREDUC_GREduc2016_E-proceedings.pdf

Isen, A. M., Daubman, K. A., \& Nowicki, G. P. (1987). Positive affect facilitates creative problem solving. Journal of Personality and Social Psychology, 52(6), 1122-1131. https://doi.org/10.1037//00223514.52.6.1122

Janisch, C., Liu, X., \& Akrofi, A. (2007). Implementing alternative assessment: Opportunities and obstacles. Educational Forum, 71(3), 221-230. https://doi.org/10.1080/00131720709335007

Johanson, G. A., \& Brooks, G. P. (2009). Initial scale development: Sample size for pilot studies. Educational and Psychological Measurement, 70(3), 394-400. https://10.1177/0013164409355692

John, M. (2018). Assessment reform in Malaysia: Policy into practice in primary schools [Doctoral dissertation, University of Stirling]. STORRE: Stirling Online Research Repository. http://hdl.handle.net/1893/29915

Kaur, A., Noman, M., \& Awang-Hashim, R. (2018). Exploring and evaluating differentiated assessment practices of in-service teachers for components of differentiation. Teaching Education, 30(2), 160-176. https://doi.org/10.1080/10476210.2018.1455084

Koshy, S. (2013). Differentiated assessment activities: Customising to support learning. In P. Bartholomew, N. Courtney, \& C. Nygaard (Eds.), Quality enhancement of university teaching and learning (pp. 37). Libri Publishing.

Lawrence, R., Ching, L. F., \& Abdullah, H. (2019). Strengths and weaknesses of education 4.0 in the higher education institution. International Journal of Innovative Technology and Exploring Engineering, 9(2S3), 511-519. https://doi.org/10.35940/ijitee.b1122.1292s319

Lawrence-Brown, D. (2004). Differentiated instruction: Inclusive strategies for standards-based learning that benefit the whole class. American Secondary Education, 32(3), 34-62. https://www.jstor.org/stable/ 41064522 
Lawson-Body, A., Willoughby, L., Lawson-Body, L., \& Tamandja, E. M. (2018). Students' acceptance of ebooks: An application of UTAUT. Journal of Computer Information Systems, 60(3), 256-267. https://doi.org/10.1080/08874417.2018.1463577

Letina, A. (2015). Primjena tradicionalnih i alternativnih oblika vrednovanja učeničkih postignuća u nastavi prirode i društva. [Application of traditional and alternative assessment in science and social studies teaching]. Croatian Journal of Education, 17(1), 137-152. https://doi.org/10.15516/cje.v17i0.1496

Lin, J. W., \& Lai, Y. C. (2019). User acceptance model of computer-based assessment: Moderating effect and intention-behaviour effect. Australasian Journal of Educational Technology, 35(1). https://doi.org/ 10.14742/ajet.4684

Llewellyn, D. (2002). Inquiry within: Implementing inquiry-based science standards. Corwin Press.

Loh, C. Y. R., \& Teo, T. C. (2017). Understanding Asian students learning styles, cultural influence and learning strategies. Journal of Education \& Social Policy, 7(1), 194-210. http://jespnet.com/journals/Vol_4_No_1_March_2017/23.pdf

Ministry of Education. (2013). Malaysia education blueprint 2013-2025 (Preschool to post-secondary education). Ministry of Education Malaysia. https://www.moe.gov.my/menumedia/mediacetak/penerbitan/dasar/1207-malaysia-education-blueprint-2013-2025/file

Ministry of Education. (2015). Malaysia education blueprint 2015-2015: Higher education. Kementerian Pendidikan Malaysia. https://www.kooperation-international.de/uploads/media/3._Malaysia_Educa tion_Blueprint_2015-2025_Higher_Education_.pdf

Mohtar, T. M. T. (2010). The use of alternative assessment to sustain teaching and learning. Penerbit UPSI.

Moon, R. T., Brighton, C. M., \& Tomlinson, C. A. (2020). Using differentiated classroom Assessment to enhance student learning [eBook edition]. Routledge. https://doi.org/10.4324/9780429452994

Nasri, N., Roslan, S. N., Sekuan, M. I., Bakar, K. A., \& Puteh, S. N. (2010). Teachers' perception on alternative assessment. Procedia-Social and Behavioural Sciences, 7(C), 37-42. https://doi.org/10.1016/j.sbspro. 2010.10.006

Newstead, S. E., \& Findlay, K. (1997). Some problems with using examination performance as a measure of teaching ability. Psychology Teaching Review, 6, 23-30.

Nguyen, T. T. M., \& Nguyen, T. D. (2010). Determinants of learning performance of business students in a transitional market. Quality Assurance in Education, 18(4), 304-316. https://doi.org/10.1108/ 09684881011079152

Noguera, P., Darling-Hammond, L., \& Friedlaender, D. (2015). Equal opportunity for deeper learning. Jobs for the Future. https://files.eric.ed.gov/fulltext/ED560802.pdf

Noman, M., \& Kaur, A. (2014). Differentiated assessment: A new paradigm in assessment practices for diverse learners. International Journal of Education and Applied Sciences, 1(4), 167-174.

Norazilawati, A., Noorzeliana, I., Mohd Sahandri, G. H., \& Saniah, S. (2015). Planning and implementation of school-based assessment (SBA) among teachers. Procedia-Social and Behavioural Sciences, 211, 247254. https://doi.org/10.1016/j.sbspro.2015.11.031

NSW Education Standards Authority. (n.d.) Differentiated assessment. https://syllabus.nesa.nsw.edu.au/ support-materials/differentiated-assessment/

Pallant, J. (2016). SPSS survival manual: A step by step guide to data analysis using SPSS program. McGrawHill Education.

Saldaña, J. (2009). The coding manual for qualitative researchers. SAGE. 
Shute, V. J., \& Rahimi, S. (2017). Review of computer-based assessment for learning in elementary and secondary education. Journal of Computer Assisted Learning, 33(1), 1-19. https://doi.org/10.1111/jcal. 12172

Suki, N. M., \& Suki, N. M. (2017). Determining students' behavioural intention to use animation and storytelling applying the UTAUT model: The moderating roles of gender and experience level. The International Journal of Management Education, 15(3), 528-538. https://doi.org/10.1016/j.ijme.2017. 10.002

Suprayogi, M. N., Valcke, M., \& Godwin, R. (2017). Teachers and their implementation of differentiated instruction in the classroom. Teaching and Teacher Education, 67, 291-301. https://doi.org/10.1016/ j.tate.2017.06.020

Swaran Singh, C. K., \& Abdul Samad, A. (2012). The use of portfolio as an assessment tool in the Malaysian L2 classroom. International Journal of English Language Education, 1(1), 94-108. https://doi.org/10. 5296/ijele.v1i1.2851

Tomlinson, C. A. (2001). How to differentiate instruction in mixed-ability classrooms. Association for Supervision and Curriculum Development.

Tomlinson, C. A. (2015). Teaching for excellence in academically diverse classrooms. Society, 52(3), 203-209. https://doi.org/10.1007/s12115-015-9888-0

Tomlinson, C. A., \& Moon, T. R. (2013). Assessment and student success in a differentiated classroom. Association for Supervision and Curriculum Development.

Varsavsky, C., \& Rayner, G. (2013). Strategies that challenge: Exploring the use of differentiated assessment to challenge high-achieving students in large enrolment undergraduate cohorts. Assessment and Evaluation in Higher Education, 38(7), 789-802. https://doi.org/10.1080/02602938.2012.714739

Venkatesh, V., Morris, M. G., Davis, G. B., \& Davis, F. D. (2003). User acceptance of information technology: Toward a unified view. MIS Quarterly, 27(3), 425-478. https://doi.org/10.2307/30036540

Whitehead, A. L., Julious, S. A., Cooper, C. L., \& Campbell, M. J. (2016). Estimating the sample size for a pilot randomised trial to minimise the overall trial sample size for the external pilot and main trial for a continuous outcome variable. Statistical Methods in Medical Research, 25(3), 1057-1073. https://doi.org/10.1177/0962280215588241

Wilson, D. M., \& Narasuman, S. (2020). Investigating teachers' implementation and strategies on higher order thinking skills in school based assessment instruments. Asian Journal of University Education, 16(1), 70-84. https://doi.org/10.24191/ajue.v16i1.8991

Zitlow, C. S., \& Kohn, A. (2001). The case against standardized testing: Raising the scores, ruining the schools. The English Journal, 91(1), 112-114. https://doi.org/10.2307/821673

Correspondence: Mas Nida Md. Khambari, Faculty of Educational Studies, Universiti Putra Malaysia, Malaysia.E-mail: khamasnida@upm.edu.my 


\section{APPENDIX A}

\section{Interview Protocol}

Study title: Students' perspectives on the use of PutraPacer as a differentiated assessment tool

Time of interview:

Place:

Interviewer:

Interviewee:

Position of interviewee: Undergraduate student

Sample interview questions:

1. Tell me briefly about the activity you did just now?

2. How do you feel about using PutraPacer during the quiz?

3. Can you recall the kind of assessments that you have experienced before? E.g., Test 1 using MCQ, essay, etc.

4. How is PutraPacer different from the other assessment that you mentioned just now?

5. In your opinion, how can PutraPacer support learning?

6. How do you think PutraPacer may benefit you?

7. How do you think it may benefit other learners with different learning styles?

8. What do you like about PutraPacer? Any feature in particular?

9. What can be improved about PutraPacer?

10.Would you support the use of PutraPacer as an assessment tool? 